\title{
Linking Epigenetics to Human Disease and Rett Syndrome: The Emerging Novel and Challenging Concepts in MeCP2 Research
}

\author{
Robby Mathew Zachariah ${ }^{1,2}$ and Mojgan Rastegar ${ }^{1,2,3}$ \\ ${ }^{1}$ Regenerative Medicine Program, University of Manitoba, 745 Bannatyne Avenue, Winnipeg, MB, Canada R3E 0J9 \\ ${ }^{2}$ Department of Biochemistry and Medical Genetics, University of Manitoba, 745 Bannatyne Avenue, Winnipeg, MB, Canada R3E 0J9 \\ ${ }^{3}$ Department of Immunology, University of Manitoba, 745 Bannatyne Avenue, Winnipeg, MB, Canada R3E 0J9
}

Correspondence should be addressed to Mojgan Rastegar, rastegar@cc.umanitoba.ca

Received 31 August 2011; Accepted 15 November 2011

Academic Editor: Hansen Wang

Copyright (C) 2012 R. M. Zachariah and M. Rastegar. This is an open access article distributed under the Creative Commons Attribution License, which permits unrestricted use, distribution, and reproduction in any medium, provided the original work is properly cited.

\begin{abstract}
Epigenetics refer to inheritable changes beyond DNA sequence that control cell identity and morphology. Epigenetics play key roles in development and cell fate commitments and highly impact the etiology of many human diseases. A well-known link between epigenetics and human disease is the X-linked MECP2 gene, mutations in which lead to the neurological disorder, Rett Syndrome. Despite the fact that MeCP2 was discovered about 20 years ago, our current knowledge about its molecular function is not comprehensive. While MeCP2 was originally found to bind methylated DNA and interact with repressor complexes to inhibit and silence its genomic targets, recent studies have challenged this idea. Indeed, depending on its interacting protein partners and target genes, MeCP2 can act either as an activator or as a repressor. Furthermore, it is becoming evident that although Rett Syndrome is a progressive and postnatal neurological disorder, the consequences of MeCP2 deficiencies initiate much earlier and before birth. To comprehend the novel and challenging concepts in MeCP2 research and to design effective therapeutic strategies for Rett Syndrome, a targeted collaborative effort from scientists in multiple research areas to clinicians is required.
\end{abstract}

\section{Introduction}

The term epigenetics refers to inheritable changes in gene expression that control cellular phenotype and fate decisions without alterations in the underlying DNA sequence [1]. In eukaryotes, two main epigenetic regulations are exerted through modifications on DNA and DNA-bound histone proteins. In general, histone modifications are dynamic and include acetylation, methylation, isomerization, phosphorylation, sumoylation, and ubiquitination $[1,2]$. The combination of such modifications confers enormous flexibility in terms of functional response of an individual cell towards extracellular signals and environmental stimuli. Certain modifications such as histone methylation can display additional layers of complexity regarding their methylation degree and undergo mono-, di-, or tri-methylation of lysine residues $[2,3]$. Furthermore, combinations or sequential additions of different histone marks can affect the chromatin organization and subsequently alter the expression of the corresponding target genes [4]. Conventionally, DNA methylation was considered to be a stable epigenetic mark, although this notion is being challenged by recent reports of active DNA demethylation [5]. In mammals, DNA methylation strictly happens at the cytosine residues in the context of $\mathrm{CpG}$ dinucleotides. The methylation of DNA molecules is processed by a group of enzymes called DNA methyltransferases (DNMTs). The mammalian DNMT family consists of 5 proteins (DNMT1, 2, 3A, 3B, 3L). DNMT1 is involved in maintaining the DNA methylation pattern during replication, while DNMT3A and DNMT3B act as de novo methyltransferases. DNMT3L is essential for the establishment of maternal genomic imprints during oocyte development, and DNMT2 is classified as part of the DNMT family; however it has very weak catalytic activity [6]. 


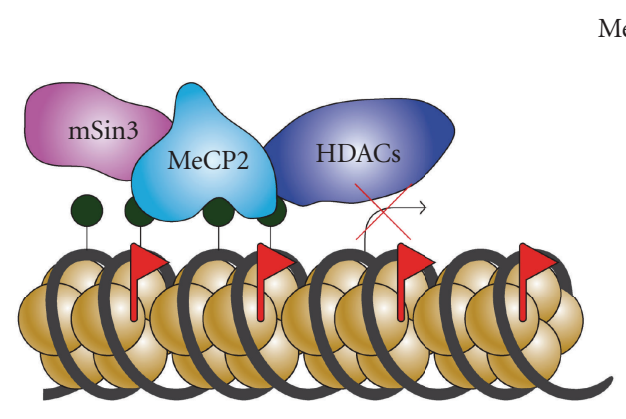

Transcriptional repression
$\mathrm{MeCP} 2$ functions

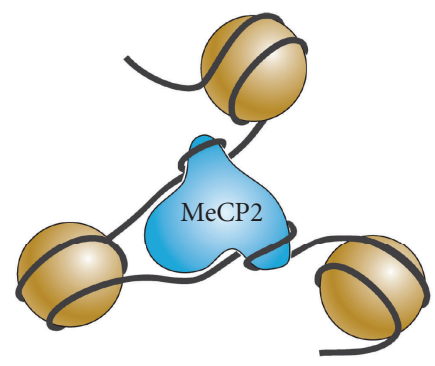

Chromatin compaction

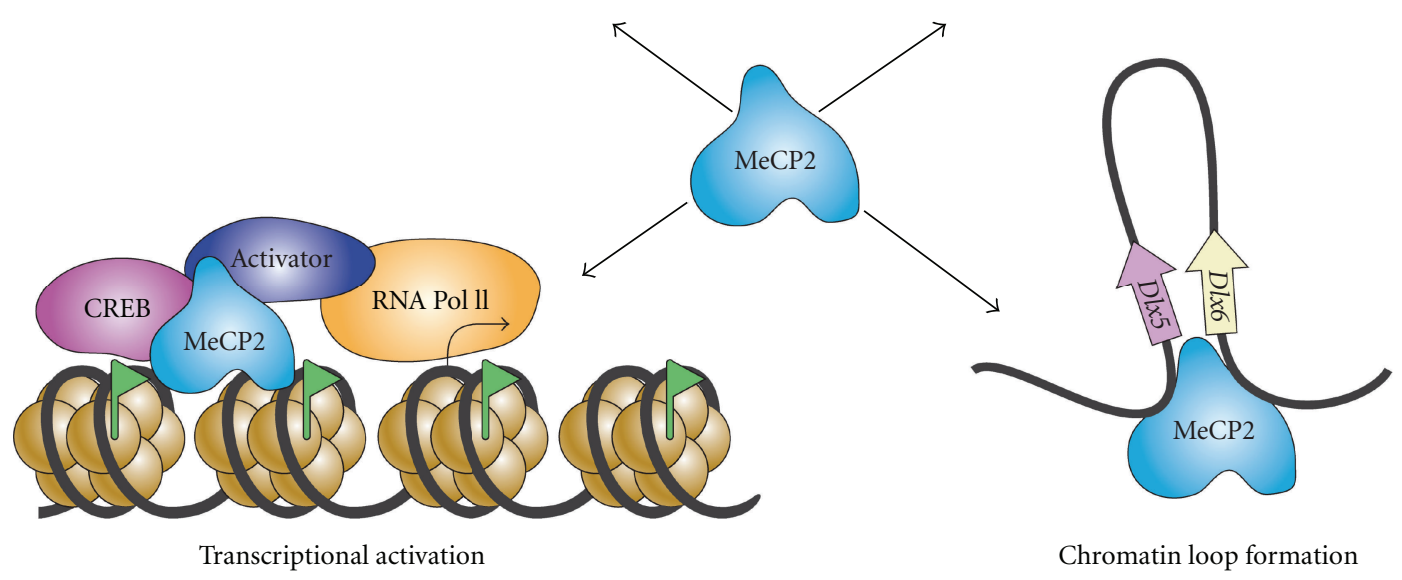

FIgure 1: The diverse functions of MeCP2 in gene regulation and chromatin organization.

DNA methylation is often associated with transcriptional repression and has been linked to the tissue-specific regulation of genes [7], expression of imprinted genes [8], and $\mathrm{X}$-chromosome inactivation in females [9]. In general, DNA methylation affects gene expression in two ways: (i) directly, by altering the binding sites of transcription factors, or (ii) indirectly, via recruitment of proteins that recognize and bind to the methylated DNA and in turn modulate gene expression. The first group of proteins that were discovered with the potential of binding to methylated DNA were the MBD (methyl-binding domain) protein family members. The mammalian MBD family consists of 5 nuclear proteins, MBD 1-4 and MeCP2 (Methyl CpG binding protein 2). With the exception of MBD3, all MBD proteins share a conserved methyl-binding domain, through which they bind to methylated DNA [10]. MBD3 lacks such ability due to a critical mutation in its MBD domain [11]. MECP2 is an X-linked gene, which was discovered as the prototype member of the DNA methyl binding proteins (MBPs) [12]. Mutations in MECP2 are the primary cause of Rett Syndrome (RTT), a neurological disorder predominantly affecting young females. RTT is characterized by an apparently normal development for the first 6-18 months after birth, followed by regression of acquired motor and language skills [1315]. In addition to Rett Syndrome, mutations in MECP2 have been observed in patients with classical autism, neonatal encephalopathy, and X-linked mental retardation [16-19].

Studies on MeCP2 have yielded surprising results in terms of the diversity of its functions (Figure 1) with enormous potential for epigenetic regulation of target gene expression. $\mathrm{MeCP} 2$ was initially identified as a methyl-binding protein [20]. Further investigations on MeCP2 function led to the discovery of its role as a transcriptional repressor and association with corepressor complexes such as $\mathrm{mSin} 3 \mathrm{~A}$ and HDACs $[21,22]$. This was not surprising, since DNA methylation itself was considered to be a repressive mark. However, a genomewide search for MeCP2 genomic distribution in SH-SY5Y cells led to two surprising observations: (i) MeCP2 was found to be associated often with transcriptionally active genes; (ii) only $2.2 \%$ of the most methylated promoters were bound by MeCP2. The presence of MeCP2 at the active promoters was later observed in mouse hypothalamus, where MeCP2 was observed to be bound to approximately $85 \%$ of genes which were misregulated by overexpression or absence of MeCP2 [23]. These studies highlight the many facets of MeCP2 functions and emphasize the need to further study its known functions. In this review, we will discuss the role of MeCP2 in chromatin structure and nuclear architecture of neurons, its competition with the linker histone $\mathrm{H} 1$, the $M E C P 2$ transcript products and diverse functional domains of MeCP2 protein, as well as $\mathrm{MeCP} 2$ expression and genomic targets in neurons and glia.

\section{The MECP2 Gene Structure and Its Splice Variants}

The MECP2 gene maps between L1CAM and the RCP/GCP loci in Xq28 and undergoes X-Chromosome Inactivation 
hMECP2 isoforms

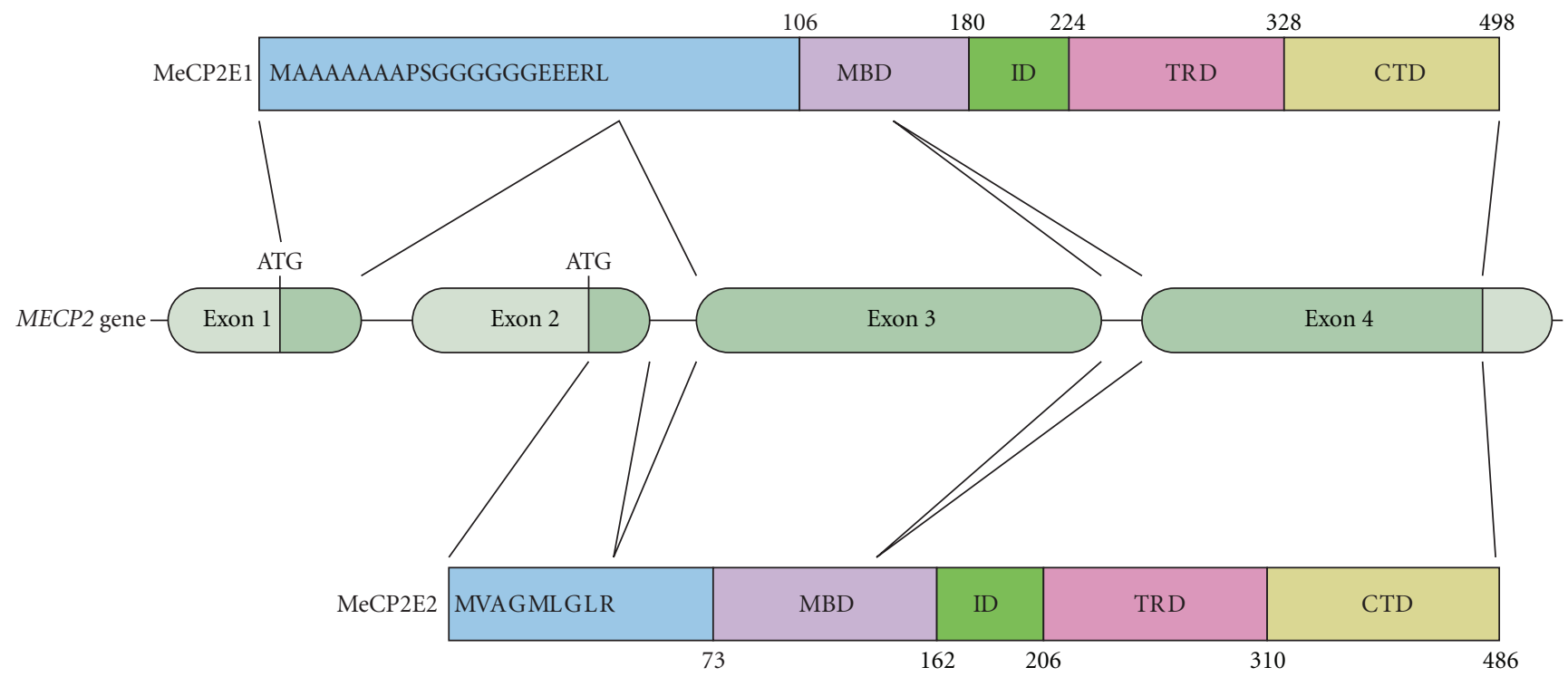

FIGURE 2: MECP2 gene and protein isoforms. Schematic illustration of the gene structure of MECP2 and the different domains of the two protein isoforms, MeCP2E1 and MeCP2E2. The primary amino acid composition of the N-terminus of MeCP2E1 and MeCP2E2 is depicted.

(XCI) in females [24, 25]. The genomic locus of MECP2 spans approximately $76 \mathrm{~kb}$ and consists of four exons encoding two different isoforms (MeCP2E1 and MeCP2E2), due to alternate splicing of exon 2 (Figure 2). The more abundant E1 isoform contains 24 amino acids encoded by exon 1 and lacks the 9 amino acids encoded by exon 2, whereas the start site for the E2 lies within the exon 2 [26]. Of the two isoforms, MECP2E1 is more efficiently translated and show $10 \mathrm{X}$ more expression than MECP2E2 in brain. Mecp2 has a large, highly conserved $3^{\prime}$ UTR that contains multiple polyadenylation sites. Alternative $3^{\prime}$ UTR usage leads to three distinct transcripts, short $1.8 \mathrm{~kb}$ and long $10 \mathrm{~kb}$ transcripts, with the latter including a highly conserved $(8.5 \mathrm{~kb}) 3^{\prime} \mathrm{UTR}$, and a third additional low abundance transcript of approximately $5-7 \mathrm{~kb}$ [27]. MeCP2 is a nuclear protein that is mainly colocalized with densely methylated heterochromatin in mouse cells. The differential expression of Mecp2/MECP2 transcripts can be subjected to tissue- and developmental stagespecific regulation. In the brain, differential transcript expression patterns for the two isoforms have been detected [28]. The transcript levels are high during embryogenesis with a postnatal decrease, but increasing again towards adulthood. On the other hand, the protein levels are low during embryogenesis and increase postnatally upon neuronal maturation [29].

$\mathrm{MeCP} 2 \mathrm{E} 1$ and $\mathrm{E} 2$ isoforms only differ in their $\mathrm{N}$-terminal sequences, sharing the functional MBD and Transcriptional Repression Domain (TRD), and it seems likely that their functional properties overlap considerably. However, several observations point towards the possibility that the two isoforms might indeed have subtle yet etiologically relevant nonredundant functions. The MeCP2E1 isoform has a putative serine residue within its $\mathrm{N}$-terminus, which is absent in MeCP2E2 isoform [26]. Furthermore, differential expression of the two isoforms at the transcript level has been demonstrated in the developing mouse brain. Mecp2E2 mRNA was enriched in the dorsal thalamus and layer $\mathrm{V}$ of the cerebral cortex, while more Mecp2E1 transcripts were detected in the hypothalamus than in the thalamus between P1 and P21 [28]. Whether this reflects a similar variation of the protein expression pattern remains to be determined. Mutation analysis in RTT patients has shown that exon 1 mutations can lead to severe RTT phenotypes. Some of these mutations do not seem to affect the transcription of $\mathrm{MeCP} 2 \mathrm{E} 2$, suggesting that MeCP2E2 alone might not be able to compensate for the loss of MeCP2E1. Although mutations in all domains of MeCP2 have been identified in RTT patients, none have been reported to be in the MeCP2E2specific exon 2. However, a number of point mutations have been identified that are unique to the MeCP2E1, indicating that MeCP2E1-specific mutations are sufficient to cause RTT. The possibility of functional redundancy between the two isoforms has been further investigated recently by a group studying the RTT phenotype rescue capabilities of each isoform. This study showed that MeCP2E1 alone is capable of compensating for overall MeCP2 deficiency in mice, in a dose-dependent manner. While MeCP2E2 also achieved phenotypic rescue, the degree of rescue was significantly higher with MeCP2E1, even at lower dosage levels [30]. The results of this study suggest that the two isoforms have both redundant and nonredundant functions.

\section{MeCP2 Protein Structure, Interacting Protein Partners and Posttranslational Modifications}

The main functional domains of $\mathrm{MeCP} 2$ are the $\mathrm{MBD}$, the TRD, and the C-Terminal Domain (CTD). The MBD facilitates binding to methylated $\mathrm{CpG}$ dinucleotides and the preference for adjacent A/T-rich motifs [31]. It is also capable 
of binding to nonmethylated DNA sequences such as the four-way DNA junctions [32]. However, the role of MeCP2 as a transcriptional repressor is mostly mediated through its TRD domain. The TRD interacts with corepressor complexes such as $\mathrm{mSin} 3 \mathrm{~A}$, further recruiting HDAC1 and HDAC2, and thereby acting as a link between DNA methylation and chromatin remodelling [21]. The TRD domain further facilitates MeCP2 interaction with other partners including c-SKI [33], YY1 [34], and YB1 [35]. MeCP2 CTD is believed to have critical functions, as transgenic mice lacking MeCP2 CTD display many RTT phenotypes [36]. Recently, MeCP2 has been shown to have dual functions, also acting as a transcriptional activator via interaction with CREB [23], although no interacting domain has been mapped. In vitro, MeCP2 is known to influence chromatin compaction and nucleosome clustering [37]. In neurons, $\mathrm{MeCP} 2$ is also known to suppress spurious transcription of repetitive elements, thereby reducing "transcriptional noise" $[38,39]$.

A crucial aspect of MeCP2 that has not been fully explored is the functional effect of its Posttranslational Modifications (PTMs). Although several modifications have been detected for MeCP2, only two phosphorylation modifications have been studied in detail. Of these, phosphorylation of serine 421 (S421) is linked to neuronal activity and is known to modulate MeCP2-regulated Bdnf transcription [40]. Interestingly, phosphorylation of serine $80(\mathrm{~S} 80)$ is removed upon neuronal activity [41]. The same group detected two other phosphorylations, S399 and S424, in resting and active neurons, respectively. It would be interesting, however, to characterize any potential cross-talk between these specific PTMs in MeCP2, as seen in histones [42, 43]. Furthermore, knock-in mice models of S80 and S421/S424 showed opposing effects of the modifications on locomotor activity, implying differential function of MeCP2 based on its PTM [41]. This shows that MeCP2 PTMs enhances its capability to function dynamically within neurons, thus emphasizing the necessity of characterizing other PTMs of $\mathrm{MeCP} 2$.

\section{The Expression Pattern of MeCP2}

MeCP2 is widely expressed among various tissues, with higher expression in the brain. Expression studies in rodents, macaque, and humans have revealed a similar pattern of heterogeneous MeCP2 expression in brain [29, 44-49]. $\mathrm{MeCP} 2$ expression pattern within different brain regions follows the developmental maturation of the central nervous system, being initially detected in the earliest developing structures such as brainstem and thalamus [29, 49, 50]. In rodents, MeCP2 expression in the olfactory bulb precedes synaptogenesis $[47,48]$. In general, MeCP2 expression is highest in neurons, with lower levels of the protein being detected in glia [51]. Within neurons, MeCP2 expression is lower in immature neurons and highest in postmitotic neurons [52]. The elevated levels of MeCP2 expression in mature neurons are maintained throughout adulthood, implying its importance in postmitotic neuronal function. To understand how MeCP2 deficiency impairs brain function, much effort has been focused on the neuronal cell-autonomous effects of MeCP2 deficiency, due to its high expression in mature neurons. Previous data indicate that MeCP2 deficiency in neurons is sufficient to cause RTT-like neurological phenotypes in mouse [53]. Recent studies investigating the effects of Mecp2 deletion in specific neuronal population have observed differential phenotypic outcomes [54, 55]. These observations imply that various RTT phenotypes might be generated as a consequence of MeCP2 deficiency in specific neuronal populations. To date, a possible contribution of astrocyte dysfunction to RTT has not been fully examined, mainly due to the previous assumption that MeCP2 is not expressed in astrocytes.

In 2009, MeCP2 expression in glial cells was shown by independent groups [51, 56, 57], with significantly lower detection of MeCP2 in glia compared to neurons. MeCP2 deficient astrocytes showed functional abnormalities and were unable to support proper neuronal growth. Furthermore, MeCP2 deficient neurons were capable of exerting a nonautonomous effect on MeCP2 wild type astrocytes, and negatively regulating them. Another study on MeCP2 expression in microglia showed that MeCP2 deficiency in microglia leads to elevated secretion of glutamate and contributes to neuronal abnormalities in RTT. Perhaps the strongest evidence to support the effect of MeCP2 expression in astrocytes in RTT etiology comes from a recent study in which MeCP2 was reexpressed specifically in astrocytes of an RTT mice model. Reexpression of MeCP2 in astrocytes alone significantly improved several phenotypes including improved locomotion and prolonged lifespan. Restoration of MeCP2 on mutant astrocytes also led to a noncell autonomous effect on neighboring neurons, rescuing dendrite abnormalities and increasing the level of V-glut1 [58]. These studies show the critical role of glial cells in RTT pathology and warrant further investigation on MeCP2 function in glia.

\section{MeCP2 Binds to Methylated DNA and Competes with Histone $\mathrm{H} 1$ for the Internucleosomal DNA}

Eukaryotic DNA is compacted into chromatin, which is made up of nucleosome repeats $[59,60]$. The nucleosome consists of a core particle composed of a histone octamer associated with DNA and a linker DNA that connects the core particles bound by one $\mathrm{H} 1$ linker histone. The histone octamer consists of two copies of each of the four histones $\mathrm{H} 2 \mathrm{~A}, \mathrm{H} 2 \mathrm{~B}, \mathrm{H} 3$, and $\mathrm{H} 4$. Histone $\mathrm{H} 1$ or linker histone seals two rounds of DNA at its entry/exit site on the surface of the nucleosome core and thereby stabilizes higher-order chromatin structure [61]. Histone $\mathrm{H} 1$ has many variants with specificity observed among species, tissue types, and even developmental stage.

Recent studies have suggested a possible relationship between histone $\mathrm{H} 1$ and DNA methylation [62, 63]. Microarray analysis of embryonic stem cells in which three $\mathrm{H} 1$ variants ( $\mathrm{H} 1 \mathrm{c}, \mathrm{H} 1 \mathrm{~d}$, and $\mathrm{H} 1 \mathrm{e}$ ) have been silenced revealed that approximately one third of the genes showing altered 
expression pattern were regulated by DNA methylation. A quantitative reduction in the extent of DNA methylation at specific $\mathrm{CpG}$ dinucleotides within the imprinting control regions of the H19-Igf2 and Gtl2-Dlk1 gene loci was observed in these cells. It is interesting to note that most of these genes are known to be regulated by $\mathrm{MeCP} 2$ (Table 1). In vitro, $\mathrm{MeCP} 2$ can compete with histone $\mathrm{H} 1$ and bind linker DNA [64, 65]. In vivo, linker $\mathrm{H} 1$ and $\mathrm{MeCP} 2$ show similar mobility in the nucleus and share the same internucleosomal binding sites, evident by Fluorescence Recovery After Photobleaching (FRAP) studies [66, 67]. Furthermore, neuronal nuclei lacking MeCP2 show 2-fold upregulation of histone $\mathrm{H} 1$ expression [39]. These observations suggest that in neurons, $\mathrm{MeCP} 2$ and histone $\mathrm{H} 1$ may share similar functions, at least in part with respect to chromatin organization.

\section{MeCP2 Genomic Distributions and Target Genes}

By interpreting DNA methylation, $\mathrm{MeCP} 2$ modulates transcriptional repression and silencing of specific target genes. In neurons, $\mathrm{MeCP} 2$ closely tracks the intensity of methylated DNA [39]. Recent studies on MeCP2 genomic distribution, however, indicate that it occupies both methylated and unmethylated DNA [82]. Although DNA methylation is considered to be a stable modification, it is becoming evident that in the brain, reduction of DNMTs or reduced MeCP2 association may result in decreased DNA methylation, a process previously thought to be irreversible. To fully understand the functional role of $\mathrm{MeCP} 2$ in the pathobiology of RTT, and to develop effective therapeutic strategies, a comprehensive knowledge of $\mathrm{MeCP} 2$ genomic targets is essential. To this end, several research groups have attempted to identify global gene expression alterations caused by $\mathrm{MeCP} 2$ dysfunction in neuronal and nonneuronal tissues from RTT patients and mice models. However, in most cases these studies have generated only a small and mostly nonoverlapping list of target genes [23, 68-80] (Table 1). Also, direct association of these identified targets towards the pathophysiology of RTT has not been established in most of these studies. One exception to this would be Brain-Derived Neurotrophic Factor (BDNF). In 2003, two independent groups demonstrated $\mathrm{MeCP} 2$ binding to methylated $\mathrm{CpG}$ sites near the promoter III of $B d n f$ in resting neurons $[70,71]$. Membrane depolarization of these neurons by $\mathrm{KCl}$ treatment led to the dissociation of $\mathrm{MeCP} 2$ from the $B d n f$ promoter. Two mechanisms have been proposed for the dissociation of MeCP2: (i) reduced $\mathrm{CpG}$ methylation at the $\mathrm{MeCP} 2$ binding site following neuronal activation [70] and (ii) phosphorylation of $\mathrm{MeCP} 2$ at specific lysine residues [71]. Recent studies in mice models have further provided in vivo evidence for functional interactions between $\mathrm{MeCP} 2$ and Bdnf. Experiments on an RTT mice model have shown that knockout of $B d n f$ exacerbated the RTT phenotypes, whereas overexpression of $B d n f$ rescued a subset of RTT-like phenotypes [83]. ChIP-based experiments in neonatal mouse brain identified two $\mathrm{MeCP} 2$ binding sites in an imprinted gene cluster in chromosome 6 [81]. Two genes within this cluster, $D l \times 5$ and $D l x 6$, showed approximately twofold increases in expression, in MeCP2-null mice brain. The study also showed alterations in histone modifications and the formation of a higher-order chromatin loop at the silenced chromatin of the Dlx5-Dlx6 locus in wild type and the lack of formation of the chromatin loop in RTT patients. This provided evidence for a novel mode of gene repression by $\mathrm{MeCP} 2$, although a similar mechanism of repression has not been shown for any other MeCP2 targets.

\section{Human Diseases Associated with MECP2 Mutations}

$\mathrm{MeCP} 2$ mutations are mostly sporadic, occurring preferentially as $\mathrm{C}>\mathrm{T}$ transitions of $\mathrm{CpG}$ dinucleotides and mostly on the paternal $\mathrm{X}$ chromosome $[84,85]$. As mentioned earlier, MECP2 mutations are mainly associated with Rett Syndrome, a progressive postnatal neurological disorder predominantly affecting females with an incidence of 1 in 10,000 [86]. RTT is characterized by an apparently nonsymptomatic phase for the first 6-18 months of age followed by apraxia, deceleration of head growth, gait abnormalities, stereotypic hand movements, and mental retardation. The lifespan of RTT patients is variable, and some patients survive up to 70 years of age $[87,88]$. In male individuals, MECP2 mutation leads to fatal neonatal encephalopathy [89], Rett syndromelike features, and familial X-linked mental retardation with or without motor abnormalities [89-91]. Male patients with RTT usually have a short lifespan and very often develop congenital encephalopathy $[92,93]$. MECP2 mutations have been detected in more than $90 \%$ of classical RTT patients. Approximately $65 \%$ of MECP 2 mutations causing RTT can be attributed to 8 recurrent missense or nonsense mutations within the MBD (R106W, R133C, T158M, and R168X) or TRD (R255X, R270X, R294X, and R306C) [94, 95].

Previous studies have implicated possible correlations between these mutations and RTT phenotypes [14, 96]. MeCP2 mutations have also been detected, albeit in very few patients, with Prader-Willi syndrome [97], Angelman syndrome [98], nonsyndromic mental retardation [99], and autistic patients [100]. Currently, Rett Syndrome has no effective treatment. However, in RTT mice lacking Mecp2, reactivation of the Mecp2 gene after the onset of disease can rescue the disease phenotype $[101,102]$. This demonstrates the possibility of RTT gene therapy strategies, where delivering $M E C P 2$ into the affected neurons may indeed improve RTT symptoms. Creating the first generation of $M E C P 2$ isoform-specific retroviral and lentiviral gene therapy vectors, we showed their efficient and long-term expression in the adult brain-derived neural stem cells, in their neuronal progenies, and in the brain microenvironment [56]. However, the in vivo rescue effect of the gene therapy delivery of these viruses remains to be elucidated. Our studies also showed the feasibility of using the endogenous Mecp2 promoter for transgenic MECP2 expression. This is significant, since one of the critical concerns towards the design of RTT gene therapy strategy is the prevention of MECP2 
TABLE 1: Known targets of MeCP2.

\begin{tabular}{|c|c|c|c|c|}
\hline Gene target & Function & Cell/tissue type studied & $\begin{array}{l}\text { Direct association with } \mathrm{MeCP} 2 \\
\text { (cell line used for ChIP) }\end{array}$ & Reference \\
\hline PCDHB1 & Cell adhesion & \multirow{3}{*}{$\begin{array}{l}\text { Oral cancer cell lines } \\
\text { (ZA, KOSC2, HSC5, } \\
\text { NA) }\end{array}$} & Yes (SH-SY5Y) & \multirow{3}{*}[68]{} \\
\hline PCDH7 & Cell adhesion & & Yes (SH-SY5Y) & \\
\hline APBP3 & Intracellular signal transduction & & Yes (SH-SY5Y) & \\
\hline$C L U$ & Extracellular molecular chaperone & \multirow{7}{*}{$\begin{array}{l}\text { RTT patient brain } \\
\text { (frontal cortex) }\end{array}$} & No (SH-SY5Y) & \multirow{7}{*}[69]{} \\
\hline CRMP1 & $\begin{array}{l}\text { Component of semaphoring signal transduction } \\
\text { pathway }\end{array}$ & & Yes (SH-SY5Y) & \\
\hline DNMI & $\begin{array}{l}\text { Vesicular trafficking, production of microtubule } \\
\text { bundles, hydrolyzes GTP }\end{array}$ & & Yes (SH-SY5Y) & \\
\hline GNBI & $\begin{array}{l}\text { Integrates signals between receptor and effector } \\
\text { proteins }\end{array}$ & & Yes (SH-SY5Y) & \\
\hline$A P L P 1$ & Enhancer of neuronal apoptosis & & No (SH-SY5Y) & \\
\hline CO1 & Mitochondrial respiratory chain & & No (SH-SY5Y) & \\
\hline GDI1 & Regulates GDP/GTP exchange & & No (SH-SY5Y) & \\
\hline$B d n f$ & Neuronal plasticity and survival & $\begin{array}{c}\text { Mouse E14 cortical } \\
\text { culture Rat E18 cortical } \\
\text { neurons } \\
\end{array}$ & $\begin{array}{l}\text { Yes (mouse E14 cortical culture } \\
\text { Rat E18 cortical Neurons) }\end{array}$ & {$[70,71]$} \\
\hline Fxyd1 & Ion transport regulator for $\mathrm{Na}, \mathrm{K}$-ATPase & $\begin{array}{l}\text { RTT mice cerebellum } \\
\text { RTT patient's } \\
\text { brain—superior frontal } \\
\text { gyrus } \\
\end{array}$ & $\begin{array}{c}\text { Yes (adult mice brain, Mecp2 wt } \\
\text { and Mecp2 null mouse; } \\
\text { HEK293T cells) }\end{array}$ & {$[72,73]$} \\
\hline $\begin{array}{l}\text { Reln } \\
\text { Gtl2 }\end{array}$ & $\begin{array}{l}\text { Neuronal layer formation, cell-cell interactions } \\
\text { Growth suppressor }\end{array}$ & RTT mice cerebellum & Yes (adult mice brain) & {$[72]$} \\
\hline $\begin{array}{l}\text { ID1 } \\
\text { ID2 } \\
\text { ID3 } \\
\text { ID4 }\end{array}$ & Regulation of neuronal differentiation & SH-SY5Y & Yes (SH-SY5Y) & {$[74]$} \\
\hline IGFBP3 & Modulation of IGF functions & RTT mice model & Yes (HeLa cells; mice cortices) & {$[75]$} \\
\hline $\begin{array}{l}U B E 3 A \\
G A B R B 3\end{array}$ & $\begin{array}{l}\text { Ubiquitin ligase } \\
\text { GABA-A receptor }\end{array}$ & $\begin{array}{c}\text { Brain cerebral samples } \\
\text { of RTT, AS, and autism } \\
\text { patients } \\
\end{array}$ & $\begin{array}{l}\text { No (adult mouse cerebellum } \\
\text { samples) }\end{array}$ & {$[76]$} \\
\hline $\begin{array}{l}\text { Sst } \\
\text { Oprk1 } \\
\text { Gamt } \\
\text { Gprin1 } \\
\text { Mef2c } \\
\text { A2bp1 } \\
\end{array}$ & $\begin{array}{l}\text { Regulation of cell migration } \\
\text { Signal transduction } \\
\text { Organ morphogenesis } \\
\text { Neurite development } \\
\text { Neuron development and differentiation } \\
\text { RNA splicing and mRNA processing } \\
\end{array}$ & $\begin{array}{l}\text { RTT mice models } \\
\text { (Mecp2 null and Mecp2 } \\
\text { Tg) and control mice; } \\
\text { Hypothalamus }\end{array}$ & $\begin{array}{l}\text { Yes (RTT mice models (Mecp2 } \\
\text { null and Mecp2 Tg) and control } \\
\text { mice; Hypothalamus) }\end{array}$ & {$[23]$} \\
\hline$x$ Hairy $2 a$ & Neuronal differentiation & Xenopus embryos & $\begin{array}{l}\text { Yes (xenopus neurula stage } \\
\text { embryos) }\end{array}$ & {$[77]$} \\
\hline $\begin{array}{l}\text { Sgk1 } \\
\text { Fkbp5 }\end{array}$ & $\begin{array}{l}\text { Cellular stress response } \\
\text { Hormone signalling }\end{array}$ & $\begin{array}{l}\text { RTT mice model; brain } \\
\text { samples }\end{array}$ & Yes (mice brain tissue) & {$[78]$} \\
\hline Uqcrc1 & Mitochondrial respiratory chain & $\begin{array}{l}\text { RTT mice model; brain } \\
\text { samples }\end{array}$ & Yes (adult mice; whole brain) & {$[79]$} \\
\hline Crh & Stress response & $\begin{array}{l}\text { RTT mice model; brain } \\
\text { samples }\end{array}$ & Yes (RTT mice brain samples) & {$[80]$} \\
\hline$D l \times 5$ & Transcription factor & Not done & Yes (mouse brain) & {$[81]$} \\
\hline
\end{tabular}

overexpression. In humans, overexpression of $M E C P 2$ caused by duplication of the MECP2 locus leads to a variety of neurological symptoms including seizures and mental retardation [103-105]. Alternatively, drug treatments can be designed to target proteins, which may compensate for MeCP2 loss in neurons. One study, in particular, has provided great hope towards pharmacological treatment of RTT in the future. Treatment of an RTT mice model with the active peptide fragment of IGF-1 significantly improved many disease phenotypes and extended the overall lifespan of the mice 
[106]. The generation of RTT-specific iPS (induced Pluripotent Stem) cells has provided an ideal platform to analyze potential pharmacological treatments for Rett Syndrome $[107,108]$.

\section{Closing Remarks}

One of the most studied genes to link epigenetics to human disease is the $\mathrm{X}$-linked MECP2 gene. MECP2 mutations lead to Rett Syndrome and are also associated with a broad spectrum of neurological disorders. Despite the impressive progress on our understanding about $\mathrm{MeCP} 2$, there are still many fundamental questions remaining to be addressed; at the methylated DNA, does MeCP2 dimerization require hetero- or homodimerization? Do MeCP2 isoforms show differential expression and/or function in CNS and are they developmentally regulated? What are the factors that regulate $\mathrm{MeCP} 2$ expression and splicing within various tissues? And finally, does MeCP2 act as a nonspecific DNA methyl binding protein on methylated DNA or does it recognize and prefer particular sites within the genome and what is the contribution of its interacting protein partners towards defining the specificity and sensitivity of such genomic distribution? A comprehensive knowledge of these unanswered questions will help to understand how the products of a single gene, such as $M E C P 2$, have such vast functional properties.

\section{Acknowledgments}

The authors apologize that many excellent papers are not included in this paper due to the space limitation. The authors would like to thank Jeff Dixon for the art work and all members of the Rastegar lab for helpful discussions. M. Rastegar is supported by funds from the Manitoba Institute of Child Health (MICH), Scottish Rites Charitable Foundation of Canada (SRCFC, Grant 10110), Manitoba Health Research Council (MHRC) (Establishment and Operating funds), Health Sciences Centre Foundation (HSCF), Natural Sciences and Engineering Research Council of Canada (NSERC Discovery Grant 372405-2009), Canada Foundation for Innovation-Leaders Opportunity Fund (CFI-LOF), CFI Infrastructure Operating Fund (CFI-IOF), and funds from the University of Manitoba Research Grants Program (URGP). R. M. Zachariah is a recipient of MHRC-MICH studentship award.

\section{References}

[1] G. P. Delcuve, M. Rastegar, and J. R. Davie, "Epigenetic control," Journal of Cellular Physiology, vol. 219, no. 2, pp. 243-250, 2009.

[2] B. A. Barber and M. Rastegar, "Epigenetic control of Hox genes during neurogenesis, development, and disease," Annals of Anatomy, vol. 192, no. 5, pp. 261-274, 2010.

[3] J. C. Rice and C. D. Allis, "Histone methylation versus histone acetylation: new insights into epigenetic regulation," Current Opinion in Cell Biology, vol. 13, no. 3, pp. 263-273, 2001.
[4] Y. Wang, W. Fischle, W. Cheung et al., "Beyond the double helix: writing and reading the histone code," Novartis Foundation Symposium, vol. 259, pp. 3-17, 2004.

[5] J. Zhu, A. Kapoor, V. V. Sridhar, F. Agius, and J. K. Zhu, "The DNA glycosylase/lyase ROS1 functions in pruning DNA methylation patterns in arabidopsis," Current Biology, vol. 17, no. 1, pp. 54-59, 2007.

[6] M. G. Goll and T. H. Bestor, "Eukaryotic cytosine methyltransferases," Annual Review of Biochemistry, vol. 74, pp. 481514, 2005.

[7] F. Song, J. F. Smith, M. T. Kimura et al., "Association of tissuespecific differentially methylated regions (TDMs) with differential gene expression," Proceedings of the National Academy of Sciences of the United States of America, vol. 102, no. 9, pp. 3336-3341, 2005.

[8] W. Reik, A. Collick, M. L. Norris, S. C. Barton, and M. A. Surani, "Genomic imprinting determines methylation of parental alleles in transgenic mice," Nature, vol. 328, no. 6127, pp. 248-251, 1987.

[9] S. F. Wolf and B. R. Migeon, "Studies of X chromosome DNA methylation in normal human cells," Nature, vol. 295, no. 5851, pp. 667-671, 1982.

[10] B. Hendrich and A. Bird, "Identification and characterization of a family of mammalian methyl-CpG binding proteins," Molecular and Cellular Biology, vol. 18, no. 11, pp. 6538-6547, 1998.

[11] M. Saito and F. Ishikawa, "The mCpG-binding domain of human MBD3 does not bind to $\mathrm{mCpG}$ but interacts with $\mathrm{NuRD} / \mathrm{Mi} 2$ components HDAC1 and MTA2," Journal of Biological Chemistry, vol. 277, no. 38, pp. 35434-35439, 2002.

[12] J. D. Lewis, R. R. Meehan, W. J. Henzel et al., "Purification, sequence, and cellular localization of a novel chromosomal protein that binds to methylated DNA," Cell, vol. 69, no. 6, pp. 905-914, 1992.

[13] R. E. Amir, I. B. van den Veyver, M. Wan, C. Q. Tran, U. Francke, and H. Y. Zoghbi, "Rett syndrome is caused by mutations in X-linked MECP2, encoding methyl-CpGbinding protein 2," Nature Genetics, vol. 23, no. 2, pp. 185188, 1999.

[14] J. L. Neul, P. Fang, J. Barrish et al., "Specific mutations in methyl-CpG-binding protein 2 confer different severity in Rett syndrome," Neurology, vol. 70, no. 16, pp. 1313-1321, 2008.

[15] A. Rett, "Rett syndrome: history and general overview," American Journal of Medical Genetics, vol. 24, supplement 1, pp. 21-25, 1986.

[16] P. Couvert, T. Bienvenu, C. Aquaviva et al., "MECP2 is highly mutated in X-linked mental retardation," Human Molecular Genetics, vol. 10, no. 9, pp. 941-946, 2001.

[17] C. W. Lam, W. L. Yeung, C. H. Ko et al., "Spectrum of mutations in the MECP2 gene in patients with infantile autism and Rett syndrome," Journal of Medical Genetics, vol. 37, no. 12, p. E41, 2000.

[18] K. S. Beyer, F. Blasi, E. Bacchelli, S. M. Klauck, E. Maestrini, and A. Poustka, "Mutation analysis of the coding sequence of the MECP2 gene in infantile autism," Human Genetics, vol. 111, no. 4-5, pp. 305-309, 2002.

[19] N. C. Schanen, T. W. Kurczynski, D. Brunelle, M. M. Woodcock, L. S. Dure, and A. K. Percy, "Neonatal encephalopathy in two boys in families with recurrent Rett syndrome," Journal of Child Neurology, vol. 13, no. 5, pp. 229-231, 1998.

[20] R. R. Meehan, J. D. Lewis, and A. P. Bird, "Characterization of $\mathrm{MeCP} 2$, a vertebrate DNA binding protein with affinity for 
methylated DNA," Nucleic Acids Research, vol. 20, no. 19, pp. 5085-5092, 1992.

[21] X. Nan, H. H. Ng, C. A. Johnson et al., "Transcriptional repression by the methyl-CpG-binding protein MeCP2 involves a histone deacetylase complex," Nature, vol. 393, no. 6683, pp. 386-389, 1998.

[22] P. L. Jones, G. J. C. Veenstra, P. A. Wade et al., "Methylated DNA and MeCP2 recruit histone deacetylase to repress transcription," Nature Genetics, vol. 19, no. 2, pp. 187-191, 1998.

[23] M. Chahrour, Y. J. Sung, C. Shaw et al., "MeCP2, a key contributor to neurological disease, activates and represses transcription," Science, vol. 320, no. 5880, pp. 1224-1229, 2008.

[24] M. D’Esposito, N. A. Quaderi, A. Ciccodicola et al., "Isolation, physical mapping, and northern analysis of the Xlinked human gene encoding methyl CpG-binding protein, MECP2," Mammalian Genome, vol. 7, no. 7, pp. 533-535, 1996.

[25] N. Sirianni, S. Naidu, J. Pereira, R. F. Pillotto, and E. P. Hoffman, "Rett syndrome: confirmation of X-linked dominant inheritance, and localization of the gene to Xq28," American Journal of Human Genetics, vol. 63, no. 5, pp. 1552-1558, 1998.

[26] S. Kriaucionis and A. Bird, "The major form of MeCP2 has a novel N-terminus generated by alternative splicing," Nucleic Acids Research, vol. 32, no. 5, pp. 1818-1823, 2004.

[27] G. J. Pelka, C. M. Watson, J. Christodoulou, and P. P. L. Tam, "Distinct expression profiles of Mecp2 transcripts with different lengths of 3'UTR in the brain and visceral organs during mouse development," Genomics, vol. 85, no. 4, pp. 441-452, 2005.

[28] J. M. Dragich, Y. H. Kim, A. P. Arnold, and N. C. Schanen, "Differential distribution of the Mecp2 splice variants in the postnatal mouse brain," Journal of Comparative Neurology, vol. 501, no. 4, pp. 526-542, 2007.

[29] M. D. Shahbazian, B. Antalffy, D. L. Armstrong, and H. Y. Zoghbi, "Insight into Rett syndrome: MeCP2 levels display tissue-and cell-specific differences and correlate with neuronal maturation," Human Molecular Genetics, vol. 11, no. 2, pp. 115-124, 2002.

[30] B. Kerr, C. J. Soto, M. Saez, A. Abrams, K. Walz, and J. I. Young, "Transgenic complementation of MeCP2 deficiency: phenotypic rescue of Mecp2-null mice by isoform-specific transgenes," European Journal of Human Genetics, vol. 20, no. 1, pp. 69-76, 2011.

[31] R. J. Klose, S. A. Sarraf, L. Schmiedeberg, S. M. McDermott, I. Stancheva, and A. P. Bird, "DNA binding selectivity of $\mathrm{MeCP} 2$ due to a requirement for $\mathrm{A} / \mathrm{T}$ sequences adjacent to methyl-CpG," Molecular Cell, vol. 19, no. 5, pp. 667-678, 2005.

[32] T. C. Galvão and J. O. Thomas, "Structure-specific binding of $\mathrm{MeCP} 2$ to four-way junction DNA through its methyl CpGbinding domain," Nucleic Acids Research, vol. 33, no. 20, pp. 6603-6609, 2005.

[33] K. Kokura, S. C. Kaul, R. Wadhwa et al., "The Ski protein family is required for MeCP2-mediated transcriptional repression," Journal of Biological Chemistry, vol. 276, no. 36, pp. 34115-34121, 2001.

[34] G. Forlani, E. Giarda, U. Ala et al., "The MeCP2/YY1 interaction regulates ANT1 expression at 4q35: novel hints for Rett syndrome pathogenesis," Human Molecular Genetics, vol. 19, no. 16, Article ID ddq214, pp. 3114-3123, 2010.

[35] J. I. Young, E. P. Hong, J. C. Castle et al., "Regulation of RNA splicing by the methylation-dependent transcriptional repressor methyl-CpG binding protein 2," Proceedings of the National Academy of Sciences of the United States of America, vol. 102, no. 49, pp. 17551-17558, 2005.

[36] M. D. Shahbazian, J. I. Young, L. A. Yuva-Paylor et al., "Mice with truncated $\mathrm{MeCP} 2$ recapitulate many Rett syndrome features and display hyperacetylation of histone H3," Neuron, vol. 35, no. 2, pp. 243-254, 2002.

[37] P. T. Georgel, R. A. Horowitz-Scherer, N. Adkins, C. L. Woodcock, P. A. Wade, and J. C. Hansen, "Chromatin compaction by human MeCP2. Assembly of novel secondary chromatin structures in the absence of DNA methylation," Journal of Biological Chemistry, vol. 278, no. 34, pp. 32181-32188, 2003.

[38] A. R. Muotri, M. C. N. Marchetto, N. G. Coufal et al., "L1 retrotransposition in neurons is modulated by MeCP2," Nature, vol. 468, no. 7322, pp. 443-446, 2010.

[39] P. J. Skene, R. S. Illingworth, S. Webb et al., "Neuronal MeCP2 is expressed at near histone-octamer levels and globally alters the chromatin state," Molecular Cell, vol. 37, no. 4, pp. 457$468,2010$.

[40] Z. Zhou, E. J. Hong, S. Cohen et al., "Brain-specific phosphorylation of $\mathrm{MeCP} 2$ regulates activity-dependent Bdnf transcription, dendritic growth, and spine maturation," Neuron, vol. 52, no. 2, pp. 255-269, 2006.

[41] J. Tao, K. Hu, Q. Chang et al., "Phosphorylation of MeCP2 at serine 80 regulates its chromatin association and neurological function," Proceedings of the National Academy of Sciences of the United States of America, vol. 106, no. 12, pp. 4882-4887, 2009.

[42] W. Fischle, Y. Wang, and C. D. Allis, "Histone and chromatin cross-talk," Current Opinion in Cell Biology, vol. 15, no. 2, pp. 172-183, 2003.

[43] S. Winter and W. Fischle, "Epigenetic markers and their cross-talk," Essays in Biochemistry, vol. 48, no. 1, pp. 45-61, 2010.

[44] S. Akbarian, R. Z. Chen, J. Gribnau et al., "Expression pattern of the Rett syndrome gene MeCP2 in primate prefrontal cortex," Neurobiology of Disease, vol. 8, no. 5, pp. 784-791, 2001.

[45] J. M. LaSalle, J. Goldstine, D. Balmer, and C. M. Greco, "Quantitative localization of heterogeneous methyl-CpGbinding protein 2 ( $\mathrm{MeCP} 2$ ) expression phenotypes in normal and Rett syndrome brain by laser scanning cytometry," Human Molecular Genetics, vol. 10, no. 17, pp. 1729-1740, 2001.

[46] D. Balmer, J. Goldstine, Y. M. Rao, and J. M. LaSalle, "Elevated methyl-CpG-binding protein 2 expression is acquired during postnatal human brain development and is correlated with alternative polyadenylation," Journal of Molecular Medicine, vol. 81, no. 1, pp. 61-68, 2003.

[47] D. R. S. Cohen, V. Matarazzo, A. M. Palmer et al., "Expression of MeCP2 in olfactory receptor neurons is developmentally regulated and occurs before synaptogenesis," Molecular and Cellular Neuroscience, vol. 22, no. 4, pp. 417-429, 2003.

[48] S. Cassel, M. O. Revel, C. Kelche, and J. Zwiller, "Expression of the methyl-CpG-binding protein $\mathrm{MeCP} 2$ in rat brain. An ontogenetic study," Neurobiology of Disease, vol. 15, no. 2, pp. 206-211, 2004.

[49] D. Braunschweig, T. Simcox, R. C. Samaco, and J. M. LaSalle, "X-chromosome inactivation ratios affect wild-type MeCP2 expression within mosaic Rett syndrome and Mecp2-/+ mouse brain," Human Molecular Genetics, vol. 13, no. 12, pp. 1275-1286, 2004.

[50] B. C. Mullaney, M. V. Johnston, and M. E. Blue, "Developmental expression of methyl-CpG binding protein 2 is 
dynamically regulated in the rodent brain," Neuroscience, vol. 123, no. 4, pp. 939-949, 2004.

[51] N. Ballas, D. T. Lioy, C. Grunseich, and G. Mandel, "Non-cell autonomous influence of MeCP2-deficient glia on neuronal dendritic morphology," Nature Neuroscience, vol. 12, no. 3, pp. 311-317, 2009.

[52] N. Kishi and J. D. Macklis, "MECP2 is progressively expressed in post-migratory neurons and is involved in neuronal maturation rather than cell fate decisions," Molecular and Cellular Neuroscience, vol. 27, no. 3, pp. 306-321, 2004.

[53] R. Z. Chen, S. Akbarian, M. Tudor, and R. Jaenisch, "Deficiency of methyl-CpG binding protein-2 in CNS neurons results in a Rett-like phenotype in mice," Nature Genetics, vol. 27, no. 3, pp. 327-331, 2001.

[54] H. T. Chao, H. Chen, R. C. Samaco et al., "Dysfunction in GABA signalling mediates autism-like stereotypies and Rett syndrome phenotypes," Nature, vol. 468, no. 7321, pp. 263269, 2010.

[55] R. C. Samaco, C. Mandel-Brehm, H. T. Chao et al., "Loss of MeCP2 in aminergic neurons causes cell-autonomous defects in neurotransmitter synthesis and specific behavioral abnormalities," Proceedings of the National Academy of Sciences of the United States of America, vol. 106, no. 51, pp. 21966-21971, 2009.

[56] M. Rastegar, A. Hotta, P. Pasceri et al., "MECP2 isoformspecific vectors with regulated expression for Rett Syndrome gene therapy," PLoS ONE, vol. 4, no. 8, Article ID e6810, 2009.

[57] I. Maezawa, S. Swanberg, D. Harvey, J. M. LaSalle, and L. W. Jin, "Rett syndrome astrocytes are abnormal and spread MeCP2 deficiency through gap junctions," Journal of Neuroscience, vol. 29, no. 16, pp. 5051-5061, 2009.

[58] D. T. Lioy, S. K. Garg, C. E. Monaghan et al., "A role for glia in the progression of Rett-syndrome," Nature, vol. 475, no. 7357, pp. 497-500, 2011.

[59] A. L. Olins and D. E. Olins, "Spheroid chromatin units (v bodies)," Science, vol. 183, no. 4122, pp. 330-332, 1974.

[60] E. Li, "Chromatin modification and epigenetic reprogramming in mammalian development," Nature Reviews Genetics, vol. 3, no. 9, pp. 662-673, 2002.

[61] A. Ramachandran, M. Omar, P. Cheslock, and G. R. Schnitzler, "Linker histone $\mathrm{H} 1$ modulates nucleosome remodeling by human SWI/SNF," Journal of Biological Chemistry, vol. 278, no. 49, pp. 48590-48601, 2003.

[62] Y. Fan, T. Nikitina, E. M. Morin-Kensicki et al., "H1 linker histones are essential for mouse development and affect nucleosome spacing in vivo," Molecular and Cellular Biology, vol. 23, no. 13, pp. 4559-4572, 2003.

[63] Y. Fan, T. Nikitina, J. Zhao et al., "Histone H1 depletion in mammals alters global chromatin structure but causes specific changes in gene regulation," Cell, vol. 123, no. 7, pp. 1199-1212, 2005.

[64] X. Nan, F. J. Campoy, and A. Bird, "MeCP2 is a transcriptional repressor with abundant binding sites in genomic chromatin," Cell, vol. 88, no. 4, pp. 471-481, 1997.

[65] T. Ishibashi, A. A. Thambirajah, and J. Ausió, "MeCP2 preferentially binds to methylated linker DNA in the absence of the terminal tail of histone $\mathrm{H} 3$ and independently of histone acetylation," FEBS Letters, vol. 582, no. 7, pp. 11571162, 2008.

[66] T. Misteli, A. Gunjan, R. Hock, M. Bustin, and D. T. Brown, "Dynamic binding of histone H1 to chromatin in living cells," Nature, vol. 408, no. 6814, pp. 877-881, 2000.
[67] A. Kumar, S. Kamboj, B. M. Malone et al., "Analysis of protein domains and Rett syndrome mutations indicate that multiple regions influence chromatin-binding dynamics of the chromatin-associated protein MECP2 in vivo," Journal of Cell Science, vol. 121, no. 7, pp. 1128-1137, 2008.

[68] K. Miyake, T. Hirasawa, M. Soutome et al., "The protocadherins, PCDHB1 and PCDH7, are regulated by MeCP2 in neuronal cells and brain tissues: implication for pathogenesis of Rett syndrome," BMC Neuroscience, vol. 12, p. 81, 2011.

[69] J. H. Gibson, B. Slobedman, H. KN et al., "Downstream targets of methyl CpG binding protein 2 and their abnormal expression in the frontal cortex of the human Rett syndrome brain," BMC Neuroscience, vol. 11, p. 53, 2010.

[70] K. Martinowich, D. Hattori, H. Wu et al., "DNA methylationrelated chromatin remodeling in activity-dependent Bdnf gene regulation," Science, vol. 302, no. 5646, pp. 890-893, 2003.

[71] W. G. Chen, Q. Chang, Y. Lin et al., "Derepression of BDNF transcription involves calcium-dependent phosphorylation of MeCP2," Science, vol. 302, no. 5646, pp. 885-889, 2003.

[72] C. R. Jordan, H. H. Li, H. C. Kwan, and U. Francke, "Cerebellar gene expression profiles of mouse models for Rett syndrome reveal novel MeCP2 targets," BMC Medical Genetics, vol. 8, p. 36, 2007.

[73] V. Deng, V. Matagne, F. Banine et al., "FXYD1 is an MeCP2 target gene overexpressed in the brains of Rett syndrome patients and Mecp2-null mice," Human Molecular Genetics, vol. 16, no. 6, pp. 640-650, 2007.

[74] S. Peddada, D. H. Yasui, and J. M. LaSalle, "Inhibitors of differentiation (ID1, ID2, ID3 and ID4) genes are neuronal targets of MeCP2 that are elevated in Rett syndrome," Human Molecular Genetics, vol. 15, no. 12, pp. 2003-2014, 2006.

[75] M. Itoh, S. Ide, S. Takashima et al., "Methyl CpG-binding protein 2 (a mutation of which causes Rett syndrome) directly regulates insulin-like growth factor binding protein 3 in mouse and human brains," Journal of Neuropathology and Experimental Neurology, vol. 66, no. 2, pp. 117-123, 2007.

[76] R. C. Samaco, A. Hogart, and J. M. LaSalle, "Epigenetic overlap in autism-spectrum neurodevelopmental disorders: MECP2 deficiency causes reduced expression of UBE3A and GABRB3," Human Molecular Genetics, vol. 14, no. 4, pp. 483492, 2005.

[77] I. Stancheva, A. L. Collins, I. B. van den Veyver, H. Zoghbi, and R. R. Meehan, "A mutant form of MeCP2 protein associated with human Rett syndrome cannot be displaced from methylated DNA by Notch in Xenopus embryos," Molecular Cell, vol. 12, no. 2, pp. 425-435, 2003.

[78] U. A. Nuber, S. Kriaucionis, T. C. Roloff et al., "Up-regulation of glucocorticoid-regulated genes in a mouse model of Rett syndrome," Human Molecular Genetics, vol. 14, no. 15, pp. 2247-2256, 2005.

[79] S. Kriaucionis, A. Paterson, J. Curtis, J. Guy, N. MacLeod, and A. Bird, "Gene expression analysis exposes mitochondrial abnormalities in a mouse model of Rett syndrome," Molecular and Cellular Biology, vol. 26, no. 13, pp. 5033-5042, 2006.

[80] B. E. McGill, S. F. Bundle, M. B. Yaylaoglu, J. P. Carson, C. Thaller, and H. Y. Zoghbi, "Enhanced anxiety and stressinduced corticosterone release are associated with increased Crh expression in a mouse model of Rett syndrome," Proceedings of the National Academy of Sciences of the United States of America, vol. 103, no. 48, pp. 18267-18272, 2006.

[81] S. I. Horike, S. Cai, M. Miyano, J. F. Cheng, and T. KohwiShigematsu, "Loss of silent-chromatin looping and impaired 
imprinting of DLX5 in Rett syndrome," Nature Genetics, vol. 37, no. 1, pp. 31-40, 2005.

[82] D. H. Yasui, S. Peddada, M. C. Bieda et al., "Integrated epigenomic analyses of neuronal MeCP2 reveal a role for longrange interaction with active genes," Proceedings of the National Academy of Sciences of the United States of America, vol. 104, no. 49, pp. 19416-19421, 2007.

[83] Q. Chang, G. Khare, V. Dani, S. Nelson, and R. Jaenisch, "The disease progression of Mecp2 mutant mice is affected by the level of BDNF expression," Neuron, vol. 49, no. 3, pp. 341348, 2006.

[84] M. Girard, P. Couvert, A. Carrié et al., "Parental origin of de novo MECP2 mutations in Rett syndrome," European Journal of Human Genetics, vol. 9, no. 3, pp. 231-236, 2001.

[85] R. Trappe, F. Laccone, J. Cobilanschi et al., "MECP2 mutations in sporadic cases of Rett syndrome are almost exclusively of paternal origin," American Journal of Human Genetics, vol. 68, no. 5, pp. 1093-1101, 2001.

[86] H. G. Dunn, "Importance of Rett syndrome in child neurology," Brain and Development, vol. 23, supplement 1, pp. S38-S43, 2001.

[87] J. L. Neul, W. E. Kaufmann, D. G. Glaze et al., "Rett syndrome: revised diagnostic criteria and nomenclature," Annals of Neurology, vol. 68, no. 6, pp. 944-950, 2010.

[88] M. Chahrour and H. Y. Zoghbi, "The story of Rett syndrome: from clinic to neurobiology," Neuron, vol. 56, no. 3, pp. 422 437, 2007.

[89] P. Kankirawatana, H. Leonard, C. Ellaway et al., "Early progressive encephalopathy in boys and MECP2 mutations," Neurology, vol. 67, no. 1, pp. 164-166, 2006.

[90] A. K. Percy and J. B. Lane, "Rett syndrome: model of neurodevelopmental disorders," Journal of Child Neurology, vol. 20, no. 9, pp. 718-721, 2005.

[91] R. E. Amir, V. R. Sutton, and I. B. van den Veyver, "Newborn screening and prenatal diagnosis for Rett syndrome: implications for therapy," Journal of Child Neurology, vol. 20, no. 9, pp. 779-783, 2005.

[92] L. Villard, A. Kpebe, C. Cardoso, J. Chelly, M. Tardieu, and M. Fontes, "Two affected boys in a Rett syndrome family: clinical and molecular findings," Neurology, vol. 55, no. 8, pp. 11881193, 2000.

[93] K. Ravn, J. B. Nielsen, P. Uldall, F. J. Hansen, and M. Schwartz, "No correlation between phenotype and genotype in boys with a truncating MECP2 mutation," Journal of Medical Genetics, vol. 40, no. 1, p. e5, 2003.

[94] T. Bienvenu, A. Carrié, N. de Roux et al., "MECP2 mutations account for most cases of typical forms of Rett syndrome," Human Molecular Genetics, vol. 9, no. 9, pp. 1377-1384, 2000.

[95] C. Schanen, E. J. F. Houwink, N. Dorrani et al., "Phenotypic manifestations of MECP2 mutations in classical and atypical Rett syndrome," American Journal of Medical Genetics Part A, vol. 126, no. 2, pp. 129-140, 2004.

[96] A. Bebbington, A. Anderson, D. Ravine et al., "Investigating genotype-phenotype relationships in Rett syndrome using an international data set," Neurology, vol. 70, no. 11, pp. 868875, 2008.

[97] R. C. Samaco, R. P. Nagarajan, D. Braunschweig, and J. M. LaSalle, "Multiple pathways regulate $\mathrm{MeCP} 2$ expression in normal brain development and exhibit defects in autismspectrum disorders," Human Molecular Genetics, vol. 13, no. 6, pp. 629-639, 2004.

[98] P. Watson, G. Black, S. Ramsden et al., "Angelman syndrome phenotype associated with mutations in MECP2, a gene encoding a methyl CpG binding protein," Journal of Medical Genetics, vol. 38, no. 4, pp. 224-228, 2001.

[99] G. Miltenberger-Miltenyi and F. Laccone, "Mutations and polymorphisms in the human methyl CpG-binding protein MECP2," Human Mutation, vol. 22, no. 2, pp. 107-115, 2003.

[100] H. Y. Zoghbi, "MeCP2 dysfunction in humans and mice," Journal of Child Neurology, vol. 20, no. 9, pp. 736-740, 2005.

[101] E. Giacometti, S. Luikenhuis, C. Beard, and R. Jaenisch, "Partial rescue of MeCP2 deficiency by postnatal activation of MeCP2," Proceedings of the National Academy of Sciences of the United States of America, vol. 104, no. 6, pp. 1931-1936, 2007.

[102] J. Guy, J. Gan, J. Selfridge, S. Cobb, and A. Bird, "Reversal of neurological defects in a mouse model of Rett syndrome," Science, vol. 315, no. 5815, pp. 1143-1147, 2007.

[103] M. J. Friez, J. R. Jones, K. Clarkson et al., "Recurrent infections, hypotonia, and mental retardation caused by duplication of MECP2 and adjacent region in Xq28," Pediatrics, vol. 118, no. 6, pp. e1687-e1695, 2006.

[104] M. Meins, J. Lehmann, F. Gerresheim et al., "Submicroscopic duplication in Xq28 causes increased expression of the MECP2 gene in a boy with severe mental retardation and features of Rett syndrome," Journal of Medical Genetics, vol. 42, no. 2, p. e12, 2005.

[105] H. van Esch, M. Bauters, J. Ignatius et al., "Duplication of the MECP2 region is a frequent cause of severe mental retardation and progressive neurological symptoms in males," American Journal of Human Genetics, vol. 77, no. 3, pp. 442453, 2005.

[106] D. Tropea, E. Giacometti, N. R. Wilson et al., "Partial reversal of Rett syndrome-like symptoms in MeCP2 mutant mice," Proceedings of the National Academy of Sciences of the United States of America, vol. 106, no. 6, pp. 2029-2034, 2009.

[107] A. Hotta, A. Y. L. Cheung, N. Farra et al., "Isolation of human iPS cells using EOS lentiviral vectors to select for pluripotency," Nature Methods, vol. 6, no. 5, pp. 370-376, 2009.

[108] M. C. N. Marchetto, C. Carromeu, A. Acab et al., "A model for neural development and treatment of rett syndrome using human induced pluripotent stem cells," Cell, vol. 143, no. 4, pp. 527-539, 2010. 

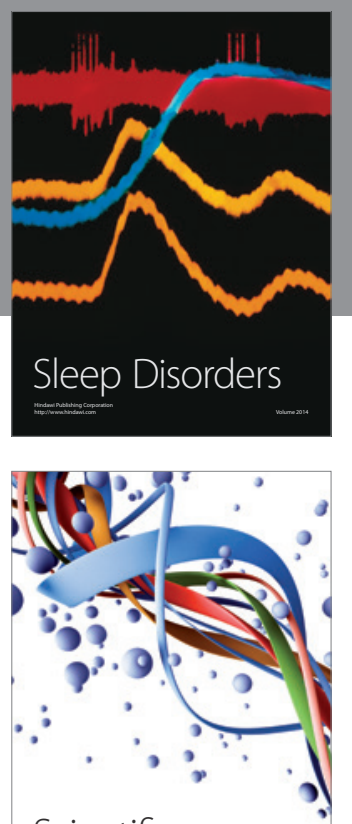

Scientifica

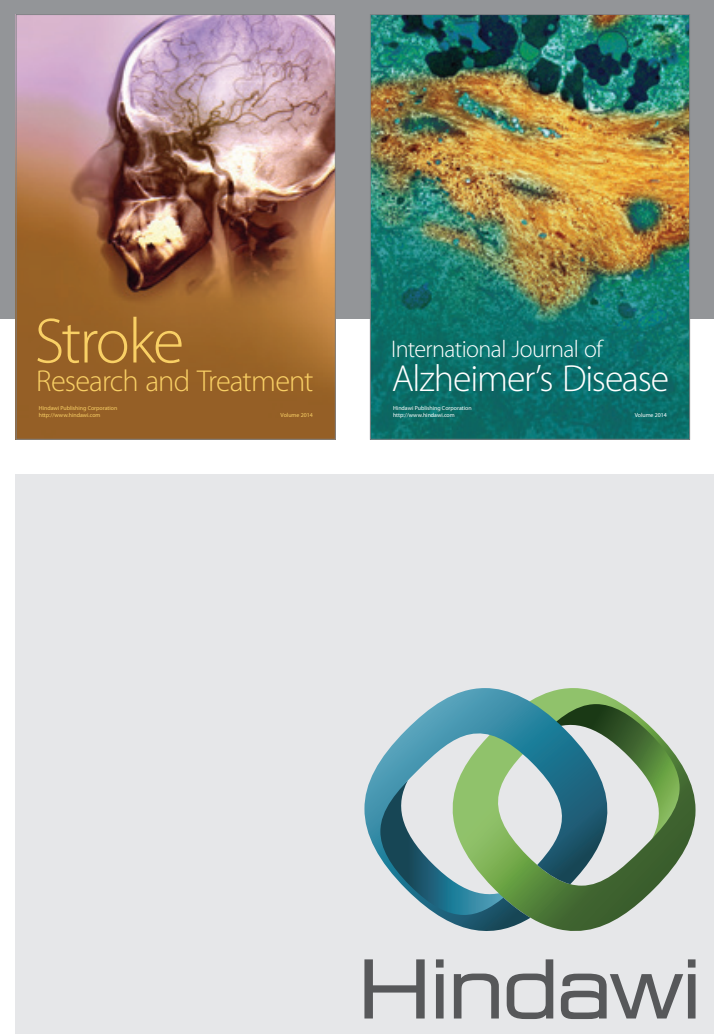

Submit your manuscripts at

http://www.hindawi.com
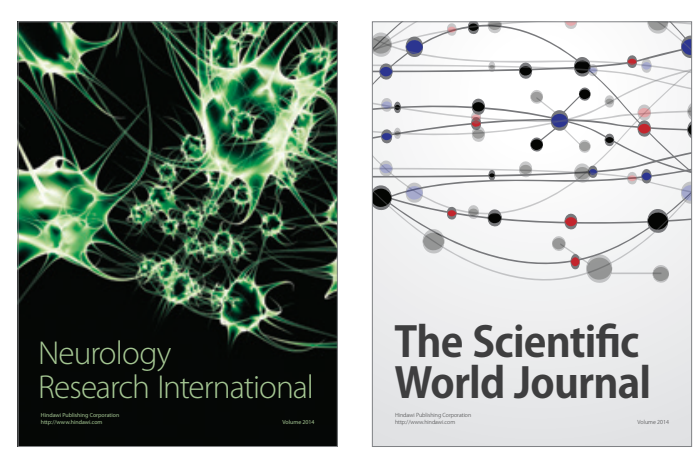

The Scientific World Journal

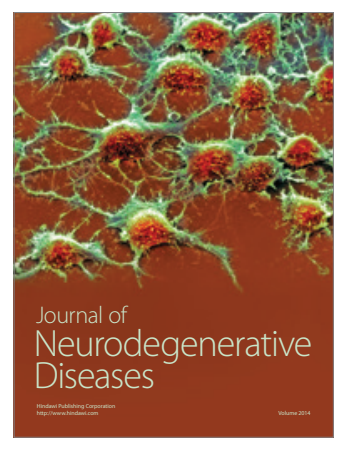

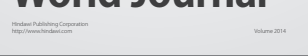

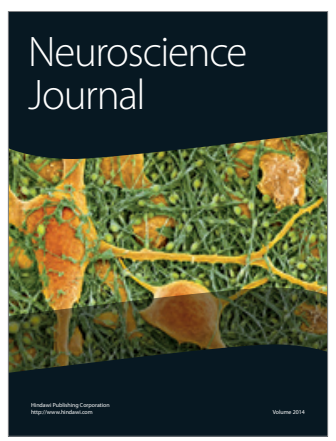

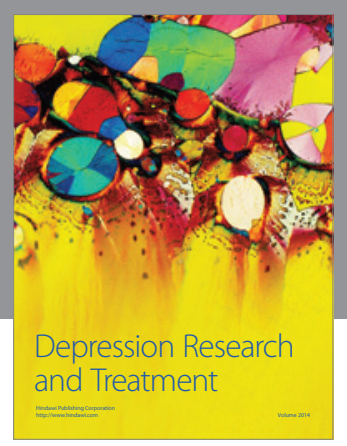
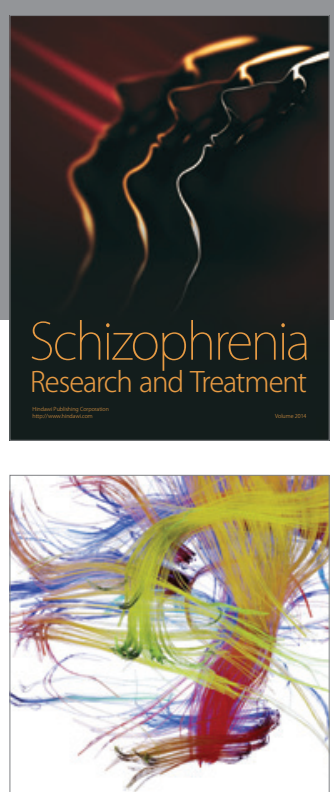

Brain Science

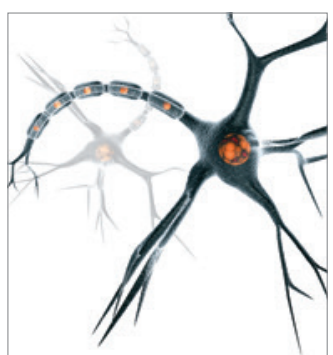

Neural Plasticity
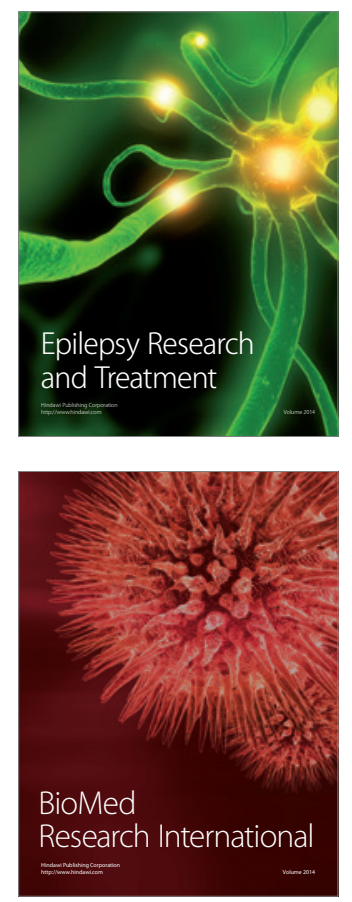

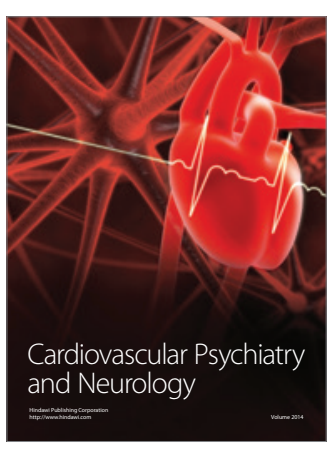

Parkinson's

Disease
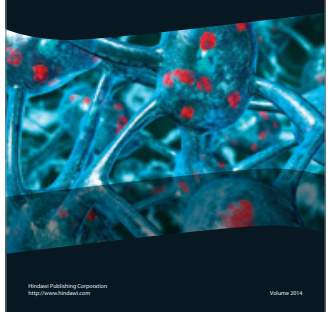